\title{
Comprehensive Evaluation of Entropy-hierarchical Grey Correlation Analysis for Highway Safety Life Protection Engineering
}

\author{
Jin Shuxin, Cao Xudong \\ School of Highway, Chang'an University, Xi'an, China
}

\begin{abstract}
Different highway safety life protection engineering decision-making have important meaning. The achieving goals and optimal highway safety life protection engineering scheme can not only improve the function of the highway facilities and service level, still can reduce the traffic accident, which caused by the imperfect highway facilities. Different highway safety life protection engineering decision-making is a multiple targets, multi-layers and multi-schemes system evaluation problem. With regard to lack of concrete data on multiple targets, multi-layers and multi-schemes system evaluation problem, make analytical hierarchy process combined with the entropy value analysis into the grey relational comprehensive evaluation method, and then get entropy-hierarchical grey correlation analysis method. This method is a qualitative and quantitative decision method, which combine comparison principle of analytic hierarchy process (AHP) and the entropy principle of entropy value analysis method to determine the relative weight of various indexes between factors layer-by-layer. Then using grey relational analysis by low-layer to high-layer step by step in the possible scheme and referenced scheme. Finally, calculating the comprehensive correlation degree between the possible scheme and referenced scheme, the best plan which has maximum grey correlation degree can be selected.
\end{abstract}

\section{Introduction}

With the rapid development of the national economy, china's highway construction has entered a glorious development period; the road traffic safety situation is getting more and more serious. China's road traffic accident death absolute toll has been the highest in the world for many years and with a higher proportion of growth, so the implementation of highway safety life protection project is particularly urgent. The scientific and reasonable decision of this important construction project will indirectly affect the local living standard of happiness and the quality of the national economy, but also has a direct impact on the accident mortality, the incidence of serious accidents and traffic safety level.

The concept of road traffic safety evaluation originated from Britain, which research work started earlier, and then successively developed the relevant content in this field [1]-[4]. Main methods of highway traffic safety evaluation in foreign countries are mostly established on the basis of a large number of traffic accident statistics to analysis for safety influence factors qualitatively [5]. It through the mathematical theory established quantitative relationship between the accident and affecting factors, so as to reflecting the level of road traffic safety. Recent research trends have shifted from absolute indicators to relative indicators as well as the studies of evaluation system and model [6], [7].In addition, some researchers also through analyze and study the changes in amount of traffic accidents before and after the reconstruction of highway structure to put forward a reasonable transformation scheme of highway system and evaluate the effectiveness of transformation, and finally established the relevant evaluation system [8].

Although the research on traffic safety evaluation started relatively lag in our country, but the relevant experts and scholars have also obtained the valuable research results to a certain extent. Wang Yuanyuan [9] structured mountainous highway accident index system based on road alignment index by using negative binomial model and carried out the traffic safety evaluation of the whole highway by evaluating the safety level of road unit. Xu Hongguo [10] discussed fuzzy setvalued statistical method to evaluate the road traffic safety, which can effectively overcome the problems that accuracy is not high caused by non quantitative indicators.

The evaluation methods of highway safety life protection engineering all have certain application scopes and defects [11-16]. Most of the quantitative models only consider the design speed test, and rarely take into account the other factors, especially when they cannot be quantified. The characteristics of various evaluation methods are compared in Table 1.

In view of the above-mentioned evaluation method of highway safety life protection engineering is lack of objectivity, this paper combine subjective weight index 
determined by AHP and objective weight determined by entropy method into comprehensive weight, which can not only take full consideration of the experience and intuition thinking, but also reduce the human uncertainty factors in the evaluation process, which both has the standard of comprehensive decision making method and reflects the higher problem solving efficiency. Then using grey relational decision method to evaluate the highway safety life protection projects. Finally, the relative optimal engineering scheme can be obtained.

Table 1. Comparison of comprehensive evaluation methods of highway safety life protection engineering

\begin{tabular}{|c|c|c|}
\hline \multicolumn{2}{|r|}{$\begin{array}{c}\text { Evaluation } \\
\text { method }\end{array}$} & Characteristics \\
\hline 1 & $\begin{array}{l}\text { Principal } \\
\text { component } \\
\text { analysis } \\
\text { method }\end{array}$ & $\begin{array}{l}\text { 1) To eliminate the correlation effect between } \\
\text { evaluation index and reduce the workload of } \\
\text { index selection; 2) Computational process can be } \\
\text { simplified and accurate evaluation results can be } \\
\text { efficient accessed; 3) Can obtain an overall } \\
\text { ranking by evaluating multiple comparison } \\
\text { objects, cannot evaluate a single object. }\end{array}$ \\
\hline 2 & $\begin{array}{c}\text { Fuzzy } \\
\text { evaluation } \\
\text { method }\end{array}$ & $\begin{array}{l}\text { 1) It has certain advantages in the multi factors } \\
\text { comprehensive evaluation; 2) Evaluation results } \\
\text { be expressed by evaluation object's membership } \\
\text { grade to the fuzzy subset, which can be more } \\
\text { intuitive and clear to interpret and evaluate; } 3 \text { ) } \\
\text { The weight of the index is determined in } \\
\text { accordance with the subjective sense of the } \\
\text { people, lack of effective objectivity. }\end{array}$ \\
\hline 3 & $\begin{array}{l}\text { Grey } \\
\text { correlation } \\
\text { degree } \\
\text { method }\end{array}$ & $\begin{array}{l}\text { 1) It has reliable theoretical foundation, clear } \\
\text { algorithm meaning and strong practicality; } 2 \text { ) It } \\
\text { can clearly and objectively reflect the pros and } \\
\text { cons of the safety level of system factors and the } \\
\text { integrated security level; } 3 \text { ) The process of } \\
\text { evaluating is simple, with good visibility. }\end{array}$ \\
\hline 4 & $\begin{array}{l}\text { Artificial } \\
\text { neural } \\
\text { network } \\
\text { evaluation } \\
\text { method }\end{array}$ & $\begin{array}{l}\text { 1) Can not only realize the multi-factors } \\
\text { comprehensive evaluation, but also realize the } \\
\text { dynamic evaluation; 2) Algorithm can be realized } \\
\text { by computer, with scientific and efficient; } 3 \text { ) } \\
\text { When the sample data is more abundant, the } \\
\text { accuracy of the model will have much room for } \\
\text { improvement; 4) The limited network training } \\
\text { samples can lead to the low training accuracy or } \\
\text { the unstable network. }\end{array}$ \\
\hline 5 & $\begin{array}{l}\text { Analytic } \\
\text { hierarchy } \\
\text { process } \\
\text { method }\end{array}$ & $\begin{array}{l}\text { 1) It is a kind of effective decision-making } \\
\text { method, which can be simple and easy to grasp } \\
\text { and has wide application scope; } 2 \text { ) Combining the } \\
\text { quantitative and qualitative analysis, it using } \\
\text { numerical to show people's subjective judgment } \\
\text { for reduce defects caused by personal factors and } \\
\text { make the evaluation results more credible. }\end{array}$ \\
\hline 6 & $\begin{array}{l}\text { Matter } \\
\text { element } \\
\text { analysis } \\
\text { method }\end{array}$ & $\begin{array}{l}\text { 1) It solves the problem of incompatibility and } \\
\text { variability between the evaluation indexes; 2) It } \\
\text { helps to judge the things from the angle of } \\
\text { change; } 3 \text { ) The index weight is determined by } \\
\text { expert opinion, which has certain subjectivity and } \\
\text { limitation. }\end{array}$ \\
\hline
\end{tabular}

In information theory, entropy is a measure of the uncertainty of things and disorder degree. The correlation degree is a measure of the correlation between the factors, which quantitatively describes the relative change between the factors. The change of the two factors' situation (direction, size, speed, etc.) is basically the same, and then the correlation between them is larger, whereas the correlation degree is smaller [17]. Grey evaluation method is using grey relation analysis theory to judge the relevance level of each evaluation index and evaluation object, so as to achieve the objective and accurate to understand the influence degree of evaluation index affected by the evaluation objects [18].

In general, the optimal solution of a multi objectives decision problem is not existed. By analytic hierarchy process (AHP) method to analyze the weight vector of decision index, and further application of the entropy technology, they can make full use of decision matrix to provide information to correct the priority weights determined by decision maker, thereby helping to form the correct decision [19-22]. On the basis of determining a reasonable weight, the optimal scheme is determined by the method of multi hierarchies grey correlation analysis according to draw up an ideal reference sequence. It can be seen that the entropy-hierarchical grey correlation analysis method is a better method to solve the multi objectives, multi layers and multi schemes evaluation problems.

\section{Selection of evaluation indicators of highway safety life protection schemes}

According to the characteristics of different highway safety protection projects, the following key characteristics can be chosen:

\section{1) Safety facilities adaptive indicators}

The more perfect of the safety facilities, the higher value of the index evaluate.

(1) The protection facilities; (2) The sign; (3) The marking; (4) The sight guidance facilities; (5) The emergency lane; (6) The deceleration facilities; (7) The passing track.

\section{2) Pavement treatment technology indicators}

(1) The disposal of the pavement diseases; (2)Preventive maintenance of pavement; (3)Regeneration technology of road surface; (4)Pavement reinforcement of reconstruction and extension.

3) daily safety and defense technical indicators

(1) The daily security defense technology for traffic participants; (2) Security management of vehicles.

4) geological hazard prevention and control indicators

(1) Prevention and control measures of geological engineering ; (2)The optimization of traffic safety facilities under geological hazard.

5) indicators of safety life protection facilities under the condition of danger

The more perfect of the safety life protection facilities, the higher value of the index evaluate.

(1)The safety measures of dangerous section; (2) Safety protection measures under accident conditions; (3)Special weather safety protection measures; (4)Security measures of lane assignments.

\section{Entropy-hierarchical grey correlation analysis model}


Assuming there are feasible schemes $A_{1}, A_{2}, \cdots, A_{i} \cdots A_{m}$, and there are two layers of evaluation indicators, the first layer index is recorded as $V_{p}, p=1,2, \cdots, r$, the second layer index is recorded as $U_{\mathrm{j}}, j=1,2, \cdots, s . x_{0}$ as a reference sequence, $x_{i}$ is the $i$ program sequence. The problem of system evaluation is transformed into selecting scheme which has the maximum correlation value. Specific steps as follows.

\section{1) Determination of analysis sequence}

The intermediate state comments set as a (very good, good, general, poor, poor, and very poor), and its membership grade is a collection $(0.8,0.7,0.6$ and $0.5,0.4,0.3$ and 0.2 ). According to the evaluation opinions of the expert group, the form of analysis sequence is:

$$
\left(x_{0}, x_{1}, \cdots x_{m}\right)=\left(\begin{array}{cccc}
x_{0}(1) & x_{1}(1) & \cdots & x_{m}(1) \\
x_{0}(2) & x_{1}(2) & \cdots & x_{m}(2) \\
\vdots & \vdots & & \vdots \\
x_{0}(r \times s) & x_{1}(r \times s) & \cdots & x_{m}(r \times s)
\end{array}\right)_{r \times s \times m}
$$

Assuming all indicators are benefit type, the reference sequence is $x_{0}=(0.8,0.8, \cdots 0.8)$.

2) The determination of indicator weight in all layers of analytic hierarchy process method

Using weight determination method of analytic hierarchy process - the root mean square method to get the weight of each indicator. The weight of $\mathrm{j}$ evaluation indicator in the second layer is $w_{j}$. Similarly, calculate the weight $w_{p}$ which between the $p$ indicators of the first layer.

3) The determination of indicator weight in all layers of entropy analysis method

The entropy of the $\mathrm{j}$ evaluation indicator of the second layer is defined as:

$$
\begin{aligned}
& H_{\mathrm{j}}=-\frac{1}{\operatorname{In} s}\left(\sum_{i=1}^{m} \frac{x_{i}(j)}{\sum_{j=1}^{s} x_{i}(j)} \operatorname{In} \frac{x_{i}(j)}{\sum_{j=1}^{s} x_{i}(j)}\right) \\
& j=1,2 \cdots s ; i=1,2, \cdots m
\end{aligned}
$$

Definition of entropy weight $v_{j}$ as follows:

$$
v_{j}=\frac{1-H_{j}}{s-\sum_{j=1}^{s} H_{j}} \quad j=1,2 \cdots s
$$

In the same way, entropy and entropy weight between the $p$ indicators of the first layer are:

$$
H_{\mathrm{p}}=-\frac{1}{\operatorname{In} r}\left(\sum_{i=1}^{m} \frac{\sum_{j=1}^{s} x_{i}(j)}{\sum_{j=1}^{s \times r} x_{i}(j)} \operatorname{In} \frac{\sum_{j=1}^{s} x_{i}(j)}{\sum_{j=1}^{s \times r} x_{i}(j)}\right)
$$

$$
\begin{gathered}
j=1,2 \cdots s ; i=1,2, \cdots m \\
v_{p}=\frac{1-H_{p}}{p-\sum_{p=1}^{r} H_{p}} \quad p=1,2 \cdots r
\end{gathered}
$$

\section{4) The calculation of comprehensive weight}

Calculating the subjective weight $w_{j}$ and $w_{p}$ by the AHP and finding the objective weight $v_{j}$ and $v_{p}$ under the theory of entropy. Combination of them will get the comprehensive weights $\lambda_{j}$ and $\lambda_{p}$. The comprehensive weights $\lambda_{j}$ which of the $\mathrm{j}$ evaluation indicator of the second layer can be expressed as:

$$
\lambda_{j}=\frac{w_{j} \times v_{j}}{\sum_{j=1}^{s} w_{j} \times v_{j}}
$$

The comprehensive weight $\lambda_{p}$ which between the $p$ indicators is:

$$
\lambda_{p}=\frac{w_{p} \times v_{p}}{\sum_{p=1}^{r} w_{p} \times v_{p}}
$$

5) System correlation analysis of candidate schemes: grey correlation analysis of the second layer The equation for calculating the grey correlation degree $\xi_{j}(i)$ which of second layer is as follows:

$$
\xi_{j}(i)=\frac{\min _{j} \min _{i}\left|x_{0}(i)-x_{j}(i)\right|+\rho \max _{j} \max _{i}\left|x_{0}(i)-x_{j}(i)\right|}{\left|x_{0}(i)-x_{j}(i)\right|+\rho \max _{j} \max _{i}\left|x_{0}(i)-x_{j}(i)\right|}
$$

The $\rho$ represents the discrimination coefficient, general takes 0.5 .

6) System correlation analysis of candidate schemes: grey correlation analysis of the first layer

The formula for calculating the grey correlation coefficient $\theta_{p}(i)$ which of first layer is as follows:

$$
\theta_{p}(i)=\sum_{j} \lambda_{j} \bullet \xi_{j}(i)
$$

Take the maximum value of a set of rows in $\theta_{p}(i)$ as reference sequence $\theta_{0}(i)$. The formula for calculating the grey correlation degree $\varsigma_{p}(i)$ which of first layer is as follows:

$$
\varsigma_{p}(i)=\frac{\min _{i}\left|\theta_{0}(i)-\theta_{j}(i)\right|+\rho \max _{i}\left|\theta_{0}(i)-\theta_{j}(i)\right|}{\left|\theta_{0}(i)-\theta_{j}(i)\right|+\rho \max _{i}\left|\theta_{0}(i)-\theta_{j}(i)\right|}
$$

7) The calculation of correlation degree between the $i$ scheme and the reference scheme

The formula for calculating the grey correlation degree $\gamma_{0 i}$ which between the $i$ scheme and the reference plan is as follows:

$$
\gamma_{0 i}=\sum_{p} \lambda_{p} \bullet \varsigma_{p}(i)
$$


8) Search for the greatest scheme correlation degree

$\max \left(\gamma_{0 \mathrm{i}}\right)$ 's scheme is the best solution.

\section{Application examples}

It is assumed that there are 3 highway traffic safety and life protection engineering schemes, denoted as scheme A, scheme B and scheme C. According to the expert group's evaluation opinion, get the quantification matrix of each index factor:

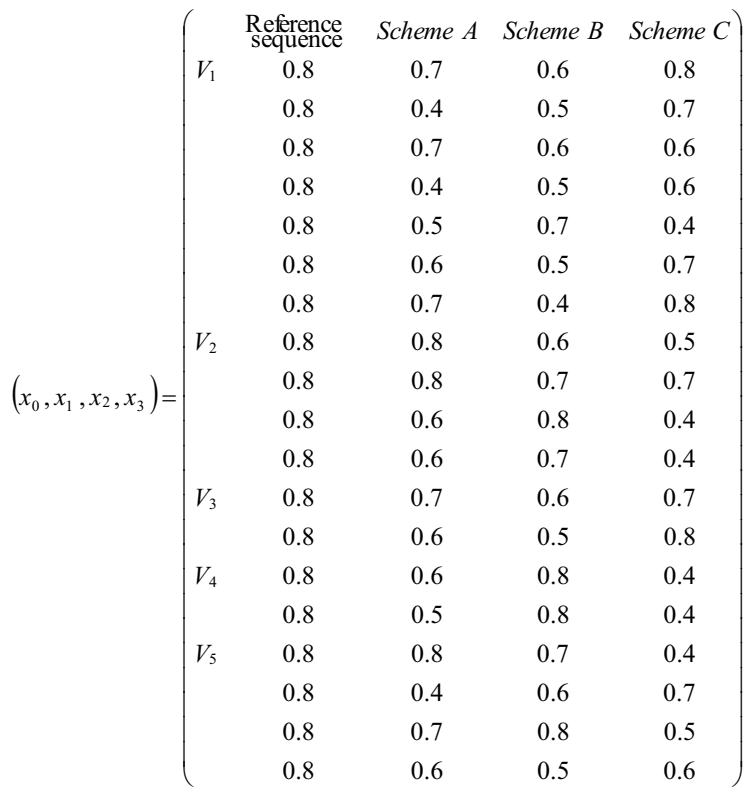

The calculation results of weight of each indicator of each layer are shown in Table 2 and Table 3 through the above steps.

Table 2. The weight of each indicator in second layer

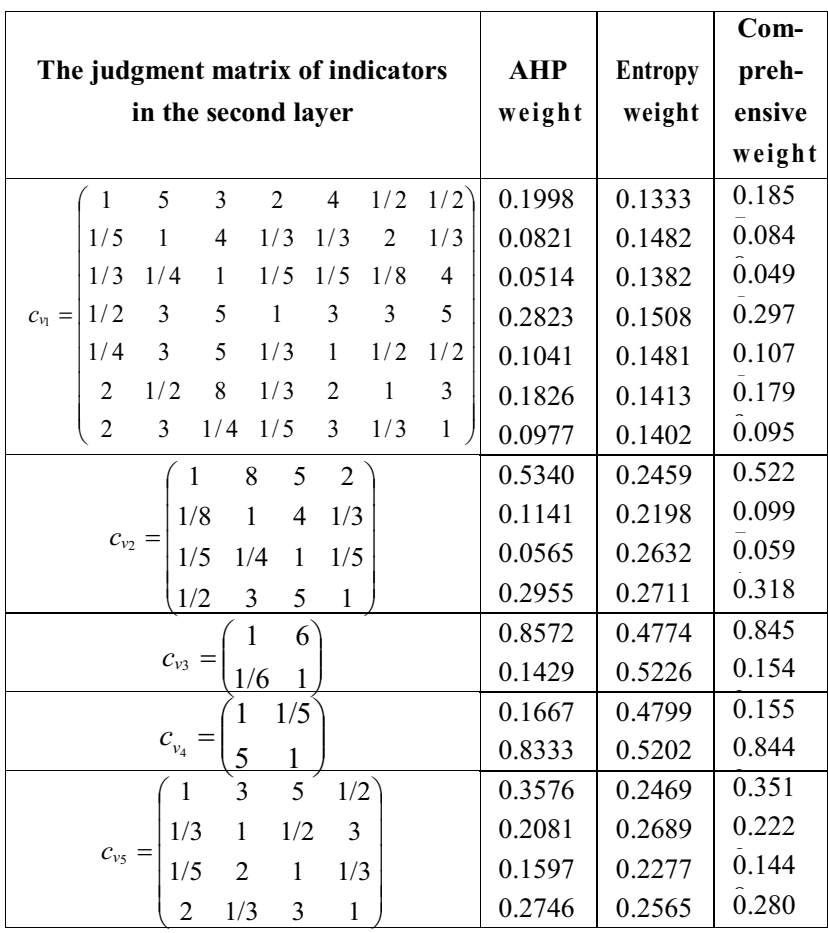

Table 3. The weight of each indicator in first layer

\begin{tabular}{|c|c|c|c|}
\hline $\begin{array}{c}\text { The judgment matrix of indicators } \\
\text { in the first layer }\end{array}$ & $\begin{array}{c}\text { AHP } \\
\text { weight }\end{array}$ & $\begin{array}{c}\text { Entropy } \\
\text { weight }\end{array}$ & $\begin{array}{c}\text { Com- } \\
\text { preh- } \\
\text { ensive } \\
\text { weight }\end{array}$ \\
\hline$C=\left(\begin{array}{ccccc}1 & 1 / 4 & 1 & 1 / 2 & 1 / 2 \\
4 & 1 & 3 & 2 & 1 / 2 \\
1 & 1 / 3 & 1 & 3 & 3 \\
2 & 1 / 2 & 1 / 3 & 1 & 2 \\
2 & 2 & 1 / 3 & 1 / 2 & 1\end{array}\right)$ & 0.1493 & 0.1571 & 0.116 \\
0.2525 & 0.1819 & 0.228 \\
0.2199 & 0.2237 & 0.244 \\
0.1892 & 0.2552 & 0.239 \\
\hline
\end{tabular}

The calculation results of correlation degree of each layer of each scheme are shown in Table 4 and Table 5 following the specific step. Among them, $\rho=0.5$.

In accordance with the correlation degree formula, we can get the calculation results of the scheme's correlation degree as shown in Table 6.

Table 4. The correlation degree of the second layer of each scheme

\begin{tabular}{|l|l|l|l|}
\hline \multirow{2}{*}{ Indicator in the first layer } & \multicolumn{3}{|c|}{ Correlation degree } \\
\cline { 2 - 4 } & $\begin{array}{l}\text { Scheme } \\
\text { A }\end{array}$ & $\begin{array}{l}\text { Scheme } \\
\text { B }\end{array}$ & $\begin{array}{l}\text { Scheme } \\
\text { C }\end{array}$ \\
\hline & 0.6667 & 0.5000 & 1.0000 \\
Safety facilities adaptive & 0.3333 & 0.4000 & 0.6667 \\
indicators $V_{1}$ & 0.6667 & 0.5000 & 0.5000 \\
& 0.3333 & 0.4000 & 0.5000 \\
& 0.4000 & 0.6667 & 0.3333 \\
& 0.5000 & 0.4000 & 0.6667 \\
\hline Pavement treatment & 0.6667 & 0.3333 & 1.0000 \\
technology indicators $V_{2}$ & 1.0000 & 0.5000 & 0.4000 \\
& 1.0000 & 0.6667 & 0.6667 \\
& 0.5000 & 1.0000 & 0.3333 \\
& 0.5000 & 0.6667 & 0.3333 \\
\hline Daily safety and defense & 0.6000 & 0.4286 & 0.6000 \\
technical indicators $V_{3}$ & 0.4286 & 0.3333 & 1.0000 \\
\hline Geological hazard prevention & 0.5000 & 1.0000 & 0.3333 \\
and control indicators $V_{4}$ & 0.4000 & 1.0000 & 0.3333 \\
\hline & 1.0000 & 0.6667 & 0.3333 \\
Indicators of safety life & 0.3333 & 0.5000 & 0.6667 \\
protection facilities under the & 0.6667 & 1.0000 & 0.4000 \\
condition of danger $V_{5}$ & 0.5000 & 0.4000 & 0.5000 \\
\hline
\end{tabular}

Table 5. The correlation coefficient and correlation degree of the first layer of each scheme

\begin{tabular}{|c|c|c|c|c|c|c|}
\hline \multirow{2}{*}{$\begin{array}{c}\text { First } \\
\text { layer }\end{array}$} & \multicolumn{2}{|c|}{$\begin{array}{c}\text { Correlation coefficients of } \\
\text { each candidate scheme }\end{array}$} & \multicolumn{3}{c|}{$\begin{array}{c}\text { Correlation degree of each } \\
\text { candidate scheme }\end{array}$} \\
\cline { 2 - 7 } & $\mathbf{A}$ & $\mathbf{B}$ & $\mathbf{C}$ & $\mathbf{A}$ & $\mathbf{B}$ & $\mathbf{C}$ \\
\hline$V_{1}$ & 0.4807 & 0.4458 & 0.6668 & 0.3747 & 0.3353 & 1.0002 \\
\hline$V_{2}$ & 0.8111 & 0.5993 & 0.4014 & 0.9998 & 0.4917 & 0.3334 \\
\hline$V_{3}$ & 0.5735 & 0.4139 & 0.6617 & 0.5843 & 0.3333 & 1.0001 \\
\hline$V_{4}$ & 0.4156 & 1.0000 & 0.3333 & 0.3632 & 0.9999 & 0.3334 \\
\hline$V_{5}$ & 0.6629 & 0.6030 & 0.4641 & 0.9996 & 0.6239 & 0.3333 \\
\hline
\end{tabular}

Table 6. The correlation degree of each scheme compared the idea scheme

\begin{tabular}{|c|c|c|c|}
\hline Scheme & A & B & C \\
\hline Correlation degree & 0.6727 & 0.5793 & 0.5739 \\
\hline Sorting & 1 & 2 & 3 \\
\hline
\end{tabular}


Therefore, the scheme A is the optimal scheme.

\section{Conclusion}

In this paper, we put forward the entropy-hierarchical grey correlation analysis method, which is a decision method of multi objectives, multi layers and multi schemes that lack of specific data, to solve the highway safety life protection engineering schemes decision problem. Its core is to use subjective comparison principle of AHP and objective entropy theory of entropy analysis method to calculate the comprehensive weight of each indicator attribute, and calculate the correlation degree of scheme by layer to rank and select the alternatives. The method not only has the characteristics of clear concept and simple calculation, but also has more objectivity than other methods. By combining the analytic hierarchy process with grey relational analysis, the decision-making of different highway safety life protection projects is more reasonable and scientific. But this is only a preliminary study to solve decision-making system problems of highway safety protection projects. Compared with other schemes, the non substitution of this method and quantitative analysis of evaluation results remains to be further in-depth study.

\section{Acknowledgment}

This research is supported by National High Technology Research and Development Program of China (Project No. 2007AA11Z248) and the Special Fund for Basic Scientific Research of Central Colleges, Chang'an University (Project No. 310821153402) and Cultivation Project for Excellent Doctorial Dissertations of Central Colleges, Chang'an University(Project No. 310821165021) and Traffic Science and Technology Project of Shaanxi Provincial Transport Department (Project No. 15-26K).

\section{References}

1. S. Protor, M. Belcher, "The use of road safety audits in Great Britain," Traffic Engineering and Control, 31(1993) :460-465.

2. AASHTO, Highway Safety Design and Operations Guide 1997. Washington D.C, AASHTO,( 2001).

3. A. Jerry Reagan, "The Interactive Highway Safety Design Model: Designing for safety by analyzing road geometrics," Public Roads, 63(1994) :215219.

4. AUSTROADS, Road safety audit, Austroads Publication Number AP-30/94, Sydney Australia, Printed by Currency Productions, AUSTROADS, (1994).

5. D. Fambro, K. Fitzpatrick and R. Koppa, "Determination of Stopping Sight Distances," NCHRP Report 400, National A-cademy Press, Washington DC, (1997).

6. K. You, L. Sun and W.Gu, "Reliability-based risk analysis of roadway horizontal curve," Transportation Engineering, 125(2012) : 137-142.
7. H. C.Chin and S. T.Quek, "Measurement of traffic con-flicts," Saf.Sci, 26, 3(1997) :169-185.

8. G. Davis, J. Hourdos and H. Xiong, "Outline of a causal theory of traffic conflicts and collisions," Proceedings of 87th Annual TRB Meeting, Washington D.C,( 2008).

9. W. Yuanyuan, "Research on the accident causations of mountain road," Beijing: Beijing Univ. Of Technology, (2008).

10. X. Hongguo, L. Zhaohui and W. Chao, "Road safety level evaluation based on grey fixed weight clustering model and factors analysis," Journal of Traffic and Transportation Engineering, 7, 2(2007):94-98.

11. L. Huichun, D.Hongxing, "A comparative study of urban expressway traffic safety evaluation method," Journal of Heilongjiang Vocational Institute of Ecological Engineering, 23, 6( 2010) : 3-6.

12. Z. Wenfeng, S. Zhongke, "Application of principal component analysis in evaluation of city road traffic safety," Computer Engineering and Applications, 43, 36(2007) : 246-248.

13. C. Dongdong, Z. Jinfa, "Fuzzy comprehensive evaluation method of traffic safety system," Hunan Communication Science and Technology, 29,3(2003) :116-117.

14. H. Wenjie, "The research of urban road traffic safety evaluation based on the BP neural network," Science Technology and Engineering, 9, 18(2009) :56075609.

15. P. Yanrong, Z. Changxu and Z. Shunying, "Road traffic safety evaluation based on the grey clustering theory and artificial neural network technology," Journal of Chongqing Jiaotong University, 24, 2(2005) :101-105.

16. W. Zijuan, Z. Jianhu and L. Jianfeng, "Study of fuzzy evaluation for urban road traffic safety based on AHP method," Journal of Minjiang University, 30, 5(2009) :106-109.

17. Y. Jiazu, The grey system theory and application, Beijing, Printed by Science Press, (1991) :214-236.

18. T. Yuejin, C.Yingwu and Y.Jinxian, Systematic engineering theory, Changsha, Printed by National University of Defense Technology Publishing, ( 1999) :38-54.

19. L. Enke, M. Yuxiang, "Grey and Analytic Hierarchy Process for Comprehensive Evaluation of Information Systems," Journal of intelligence, 20, 4(2001) : 416-420.

20. M. Rui, Z. Jiatai, "Research of hierarchy synthetic evaluation based on grey relational analysis," System Engineering Theory and Practice, 10( 2008):125130.

21. F. Zhiping, Z.Jin and M. Jian, "An integration method to determine the weight of Multiple attribute decision making," Journal of Management Science, 1, 3(1998):50-53.

22. L. Jian, "Using basic points to calculate the weighting coefficients in multiple objective decision making," System Engineering Theory and Practice, 4(2001):27-30. 